\title{
Chapter 10 \\ Academic Continuity During the \\ Covid-19 Global Health Emergency: \\ Education 4.0 and the Flexible-Digital \\ Model of Tecnologico de Monterrey \\ University in Mexico Supporting \\ Secondary Education
}

\author{
Arturo Molina, Beatriz Villegas, César Pavel Ochoa, and Jhonattan Miranda
}

\begin{abstract}
Today, new teaching-learning models, methods, and programs are emerging to guarantee academic continuity in response to the current situation caused by the global health emergency (Covid-19). This work presents how the FlexibleDigital Model of Tecnologico de Monterrey University in Mexico was designed and implemented during this emergency in this institution. This work also addresses the relevant role that technology has taken during this situation, and the concept of Education 4.0 is offered as a framework to model the presented study. Finally, two case studies that were applied at the secondary education level are presented as an example of how higher education is supporting academic continuity at the secondary level.
\end{abstract}

\footnotetext{
A. Molina $\cdot$ J. Miranda $(\square)$

School of Engineering and Sciences, Tecnologico de Monterrey,

Mexico City, Mexico

e-mail: armolina@tec.mx; jhonattan.miranda@tec.mx

B. Villegas

Bilingual Secondary School, Carlos Darwin, Irapuato, Guanajuato,

Mexico

e-mail: beatriz.villegas@tec.mx

C. P. Ochoa

Bilingual Secondary School, Tec de Monterrey, Ciudad Juárez,

Chihuahua, Mexico

e-mail: pochoa@sectec.mx
} 


\subsection{Introduction}

The global emergency caused by the new coronavirus (SARS-CoV-2) detected in China at the end of 2019, which has been identified as the cause of the Covid-19 disease, has triggered the greatest health crisis of the modern age of humanity. This has brought with it devastating social and economic effects, which will be adversely reflected in practically all sectors of society during the subsequent months and even years. Education has been one of the most affected sectors. Consequently, during the first quarter of 2020, most countries had to stop all face-to-face academic activities. For example, in Mexico, these activities were suspended in late March 2020 during the national health emergency declared by the Mexican Government, affecting about 40 million students at all educational levels, both public and private (Forbes México, 2020). Due to the uncertain outlook, most academic institutions acted immediately to provide a quick response to address academic continuity at all the educational levels.

The Tecnologico de Monterrey University in Mexico (Tecnologico de Monterrey) used its available infrastructure and, most importantly, its valuable previous experiences in digital and virtual education to provide a quick response to this extraordinary event to guarantee academic continuity, using distance learning as the main strategy. Tecnologico de Monterrey is the largest private non-profit educational system in Mexico and includes secondary school, high school, undergraduate, and postgraduate education levels, with a presence in 26 cities in Mexico. Currently, Tecnologico de Monterrey has about 90,000 students and more than 8600 professors and teachers across all educational levels.

Tecnologico de Monterrey's 30-year experience in the design and delivery of digital education programs, for both academic and continuing education, combined with the current advances in information and communication technologies (ICTs) being applied to the education sector have facilitated the design and implementation of effective distance learning programs during the last few years. Programs included the Online Postgraduate Program (9917 students reached), the Flexible and Interactive with Technology, known as "FIT courses" (7129 students reached), Continuing Online Education Programs (73,943 students reached), the MOOCs (829,165 students reached), the Telepresence Courses (1668 students reached), and more recently the Hybrid-Flexible Model, which was applied to guarantee academic continuity on the Mexico City Campus during the emergency caused by the major earthquake in 2017 (8472 students reached). Hence, experience gained by implementing these programs was used to propose a new learning model to guarantee the academic continuity during the Covid-19 global health emergency in 2020-2021.

Another relevant element to highlight is the role that technology has played throughout this situation. Today, technological evolution in digitalization, virtualization, and connectivity is playing an essential role in the generation of new learning models and education programs. Also, different factors, such as social dynamics, social challenges, access to technologies, and demography, are considered when implementing various techniques. The concept of Education 4.0 has been used as a 
reference to understand available and affordable technologies in education in terms of capacities and capabilities. Therefore, the four core components of Education 4.0 are considered during the design process of the proposed implementations and models presented in this work.

With this goal, teachers, researchers, and specialists in distance education and educational innovation at Tecnologico de Monterrey considered the current components of Education 4.0 (ICTs, key competencies, novel teaching-learning methods, and infrastructure) and related them to the current education model of Tecnologico de Monterrey (TEC21). They also drew upon previous experiences in digital and virtual education to design and propose the model called "Flexible-Digital Model (FDM)." This is an online distance program intended to guarantee a timely and effective deployment of educational services to maintain academic continuity at all educational levels at Tecnologico de Monterrey (Tecnológico de Monterrey, 2020; Miranda et al., 2019).

In this work, the concepts of Education 4.0 and the FDM are used to explain how technologies and learning methods are implemented. This work will also present two case studies from the secondary education level in two different institutions to show examples of how higher education is supporting academic continuity at the secondary level and to illustrate how the proposed FDM works.

\subsection{The Education 4.0 Concept Applied for Academic Continuity}

The term "Education 4.0" comes from the well-known concept of "Industry 4.0," which refers to the different industrial revolution periods that have taken place throughout history, with the fourth industrial revolution bringing with it a technological evolution. This technological evolution has had positive effects in different sectors, improving processes and optimizing the use of resources (Ma et al., 2019; Keser \& Semerci, 2019). Therefore, in the case of the education sector, these improvements and technological evolution are known today as Education 4.0 (Miranda et al., 2019). Figure 10.1 illustrates this concept through examples of relevant technologies and learning methods that took place in the different periods of Education 4.0.

Currently, Education 4.0 has an essential role in the design of new teachinglearning programs, especially for online distance programs, since new programs are integrating the four main components that characterize this period:

(i) ICTs. Implementation of current and emerging ICTs as resources to support the teaching-learning and operative processes. Currently, the education sector is mainly taking advantage of technologies that are powered by the Internet of things (IoT). Today, these implementations can be found and analyzed in two categories: (a) type of tools (devices and platforms) and (b) type of technology used, such as artificial intelligence, machine learning, data science, data ana- 


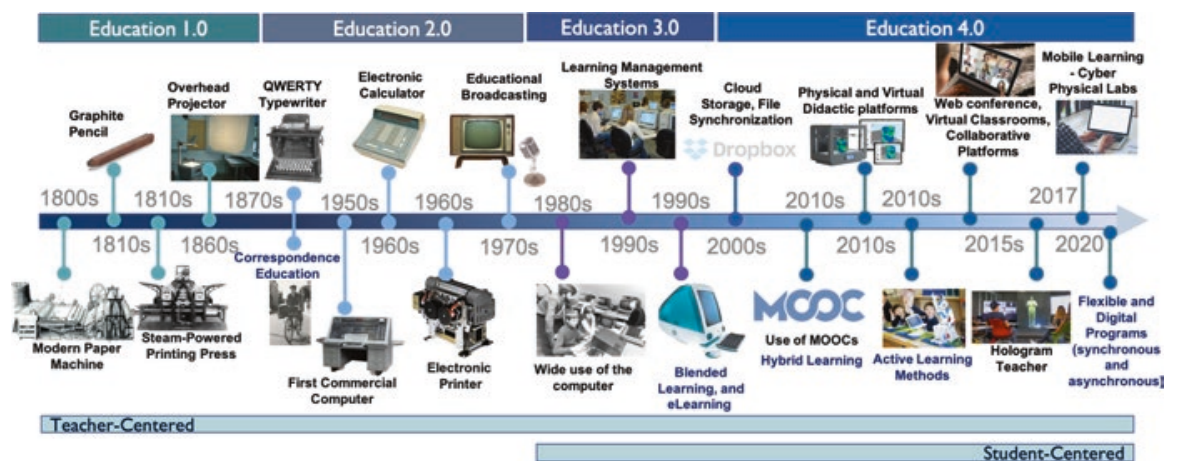

Fig. 10.1 Evolution of technologies and learning methods according to the four periods of Education, leading to Education 4.0-Timeline

lytics, cloud computing, and mixed reality, among others. In digital learning programs, these tools and technologies are essential. They are not limited only to software systems but also include physical systems such as assistant robots and cyber-physical systems, among others.

(ii) Key competencies. Training and development of key competencies, including both soft competencies and hard competencies. Examples of relevant soft competencies are innovation, leadership, creativity, critical thinking, collaboration, cooperation, and communication. Relevant hard competencies are related to the training for the use of new artifacts, tools, techniques, and emerging technologies, as well as the application of knowledge for the generation of new technologies, methods, practices, etc.

(iii) New learning methods. The incorporation of new learning methods is a crucial component for emerging teaching-learning programs since the combination of adequate infrastructure, technology, and instruction with teaching/ training times are essential for an optimal teaching-learning experience. As a result, some suitable learning methods have emerged not only to take advantage of available resources and times but also to improve teaching and learning processes. Recently, many learning techniques and methods have emerged to answer current learning problems; it has also been observed that the combination of these techniques/methods with the right technologies can considerably improve the learning process of students. Some relevant learning methods that are applied in this period are problem-based learning (PBL), challenge-based learning (CBL), learning by doing (LBD), and active learning (AL). Diverse learning methods specifically for hybrid and digital learning are also applied, such as blended learning, flipped classroom, and synchronous/asynchronous learning, among others. More recently, the incorporation of learning methods based on gamification has been widely used in digital-based learning (DBL) and flexible-digital learning (FDL). 
(iv) Infrastructure. The use of innovative facilities, services, and systems is considered to improve teaching-learning processes. New infrastructure can be considered at two levels:

(a) Institutional level. Here, adopting technology-based infrastructure and environmentally sustainable practices is considered. Examples of these facilities at this level are smart schools, virtual/digital schools, and environmentally sustainable schools. These institutions seek to provide not only better learning environments but also seek to offer spaces and best practices for recreation, comfort, sustainability, and accessibility.

(b) Classroom level. Here, infrastructure priorities include providing adequate and innovative furniture, equipment, connected tools, distance teaching tools, and other educational resources and services. Also, at this level, immersion environments and specialized laboratories are considered. In many cases, these classrooms are equipped with high-level technologies and are prepared to carry out learning through use of new learning methods.

Today, these four components can be used as a reference in the design of new learning programs, models, and projects in educational innovation. Once these components have been considered, designers can consider current social issues and make the best decisions about the type of resources to be implemented in new learning-teaching programs.

Tecnologico de Monterrey is currently implementing a new educational model called "TEC 21." Through use of the four main strategies, this model is reaching the vision and concept of Education 4.0 (Educational Model (Modelo Educativo) Tec21, 2019): (i) Challenge-Based Learning that promotes the engagement and motivation of students by performing challenging activities; (ii) Flexibility in the ways in which students are learning; (iii) Inspiring Faculty: faculty not only accompany the students in their learning process but also promote the use of emerging technologies to teach; and (iii) Memorable University Experience: this strategy promotes the use of innovative infrastructure to offer students not only an adequate learning environment but also activities for culture, sports, and recreation, among others. Consequently, by applying the vision and concept of Education 4.0, it is possible to utilize its main components to guarantee academic continuity during the global health emergency (Covid-19), taking advantage mainly of the virtual infrastructure that applies adequate learning methods. Therefore, the main strategy for academic continuity at all educational levels of the Tecnologico de Monterrey was the implementation of virtual classrooms, applying synchronous and asynchronous distance learning under the Flexible-Digital Model created specifically for this purpose. Figure 10.2 illustrates the four core components of Education 4.0 adapted to the different educational levels of Tecnologico de Monterrey. 
Education 4.0

(TEC 21 Educational Model)

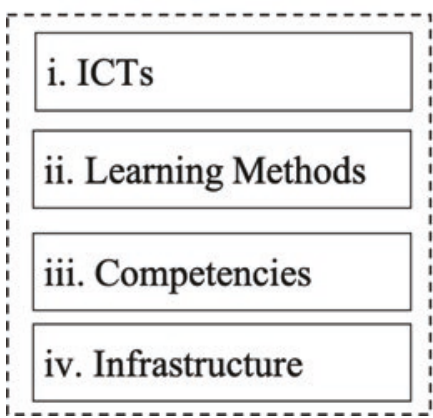

Tecnologico de Monterrey

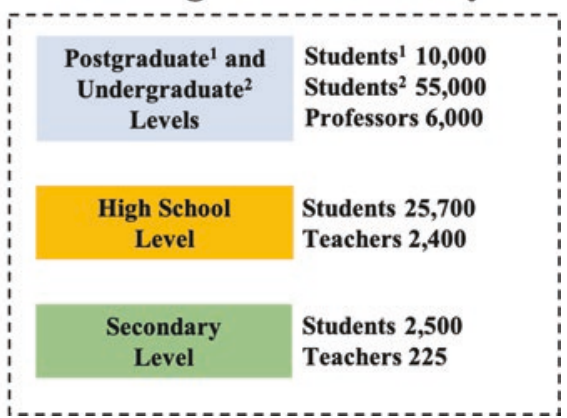

Fig. 10.2 Education 4.0 adapted to the different educational levels of Tecnologico de Monterrey

\subsection{The Flexible-Digital Model for Academic Continuity During the Covid-19 Global Health Emergency}

The Tecnologico de Monterrey was the first Mexican University to declare a contingency plan for its academic community. Therefore, with just 1 week of preparation and suspension of academic activities for students, the institution launched the Flexible and Digital Model (FDM) to guarantee academic continuity. The FDM is a learning model that integrates innovative teaching strategies with cutting-edge technologies. One of its main benefits is that it enables academic continuity to be guaranteed through a flexible and digital education strategy (Tecnológico de Monterrey, Educational Innovation Department, 2020).

Flexible: It is flexible because it ensures that the teaching-learning process can be adjusted to different needs and situations regardless of time or space factors.

Digital: It is digital because it takes advantage of educational technology to generate hybrid or distance learning experiences.

The FDM proposes the design of a flexible and digital learning experience that combines the following five core components:

(i) Technological tools. Utilizing emerging ICTs such as web-conferences, remote interaction tools, and technological platforms for content and learning management and technological applications for active learning.

(ii) Interaction. Three main didactic activities for interaction: (i) live sessions via web-conference based on active learning (synchronous), (ii) on-demand and remote advice (asynchronous), and (iii) supporting students using interactive tools.

(iii) Content. Didactic resources such as readings, presentations, websites, infographics, videos, and simulators, among others.

(iv) Learning activities. Including activities such as live sessions via webconference for supervised activities and collaborative work, and remote- 


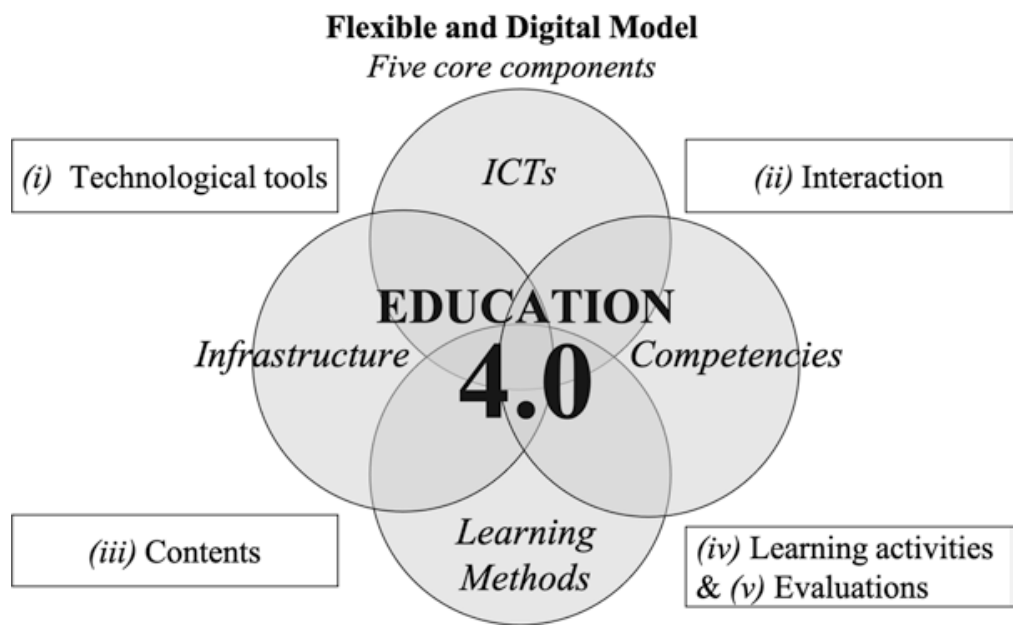

Fig. 10.3 The five core components of the FDM of Tecnologico de Monterrey

assisted work for activities such as self-directed individual work, guided collaborative work, and interactive activities using different technologies.

(v) Evaluation. The implementation of digital evaluation resources and multimodal feedback (video, audio, and/or text).

Therefore, using the four main components of Education 4.0, designers and teachers can apply emerging technologies and new learning-teaching methods, as well as make use of online infrastructure for knowledge generation and information transfer. Using this structure, the training and development of student competencies can be ensured. Figure 10.3 shows the FDM composed of the five core components proposed by the Tecnologico de Monterrey.

\subsection{The Implementation Process of the Flexible and Digital Model}

During the week before the continuation of classes, basic training for teachers on the FDM was launched through the national network of Centers for Teaching Development and Educational Innovation of Tecnologico de Monterrey with the collaboration of experts from areas such as Educational Innovation and Technologies for Education.

In addition, an overview of the FDM, guidelines, and a suggested methodology were defined so that teachers could adapt the organization of the course and consider the main aspects for its delivery. Table 10.1 summarizes these activities.

Finally, as part of this process, a technical support strategy was deployed. Different activities and programs were performed during the previous week to 
Table 10.1 The five stages of transforming a course into an FDM for academic continuity (Tecnológico de Monterrey, 2020)

\begin{tabular}{l|l}
\hline Stages & Recommendations for teachers \\
\hline recommendations & 1.1. Get ready to start (checklist of the minimum infrastructure \\
& required) \\
& 1.2. Explore the digital options that you have available to continue \\
& your course \\
& 1.3. Plan how to continue your course \\
& 1.4. Communicate with your students \\
& 1.5. Update your course on a technology platform \\
\hline 2. Platform organization & 2.1. Identify the technological platforms assigned by the institution \\
& 2.2. Select the content to be integrated onto the platform \\
& 2.3. Design the structure of your course on the platform \\
\hline 3. Flexible, digital & 2.4. Validate that your course is published correctly on the platform \\
teaching & 3.1. Share your calendar settings \\
& 3.2. Define the operational policies during academic continuity \\
& 3.3. Ensure effective communication \\
& 3.4. Establish timetables and counseling services \\
& 3.5. Teach your classes by web conference platforms \\
& 3.6. Promote cooperative work \\
& 3.7. Schedule exams on the platform you use \\
& 3.8. Ensure timely follow-up \\
& 3.9. Reinforce your students' learning through effective feedback \\
& 3.10. Enrich your students' experiences \\
\hline 4. Formats and tutorials & 4.1. Access to supporting resources \\
& 4.2. Access to support for classes design by web-conference \\
& 4.3. Access to the design of didactic resources \\
& 4.4. Tutorials for flexible-digital teaching \\
\hline 5. Open resources & 5.1. Access to a repository of open resources that can be used during \\
& classes \\
\hline
\end{tabular}

initiate the model and, during the application, implement it. Therefore, training programs for teachers related to educational technologies, pedagogy advice, and teaching-digital practices were provided. Also, additional support, such as online courses and websites, were enabled. Lastly, a support and accompaniment scheme for teachers was defined, and a communication strategy was established to keep the academic community informed.

\subsection{Case Studies: The Flexible-Digital Model Applied in the Secondary Education Level}

As part of its educational offerings, Tecnologico de Monterrey also provides secondary level education. In Mexico, the secondary education level is comparable to the lower secondary education or middle school, which is equivalent to three academic years. Students range in age from 12 to 15 years old. Currently, Tecnologico de Monterrey has seven secondary institutions located in different cities across 
Mexico with about 2500 students and 225 teachers. The proposed FDM that was implemented in higher education was also transferred to these institutions. In this section, two case studies are presented to show the understandings gained from the implementation of the FDM in two secondary institutions of Tecnologico de Monterrey.

\subsubsection{The Experience of the Bilingual Secondary School, Carlos Darwin, Irapuato, Guanajuato, Mexico}

Context The Bilingual Secondary School, Carlos Darwin-located in Irapuato, Guanajuato, Mexico-is part of the Tecnologico de Monterrey Educational System. This institution has about 370 students divided among three grade levels and 36 teachers. The FDM was implemented and adapted according to the institution's nature. Furthermore, FDM was compatible with the school's primary objective to continue with schoolwork and learning activities to fulfill the academic programs established for the 2019-2020 school year.

Implementation The implementation process for this model utilized the five stages recommended for the transformation of a course into an FDM for academic continuity, and adopted the practices and tools recommended by the Tecnologico de Monterrey University. Because the program was designed for upper-level education, the decision was made to mainly use asynchronous formats in the form of previously video-recorded classes stored in learning management systems (LMSs). This choice was made due to the prioritization of the protection of information regarding interactions with minors, and it prevents the minors from appearing in front of a camera. At the same time, the students could consult the pre-recorded sessions as many times as necessary. However, there were also synchronous meetings - mainly to highlight a specific subject or for students to receive advice — carried out with appropriate measures in place so that these events could occur with adult supervision.

As the period of home confinement was extended, some changes had to be made in the academic schedule as well as the way teaching was delivered to the students. Consequently, in some subjects-due to their complexity-more synchronous online classes were enabled to guarantee student understanding of the subjects. In the case that students could not attend these online classes, they could access the recorded classes, and the teachers always supported them via message, mainly through e-mail and instant messaging mobile apps. Special sessions were also held for low-performing students to require them to deliver work, due to the lack of completion of work during regular sessions.

Evaluation of Students The secondary education level has three formal evaluation blocks during the academic period. The contingency plan started with the beginning 
of the third evaluation block. Usually, exams serve as the main mode of assessing knowledge; in this case, exams were replaced by academic assessment projects, which were requested for all topics to complete evaluations in this last block. So then, by mainly using LMSs, students were able to find information, deliver their projects, get feedback, and receive evaluation results.

Given the nature of the subjects of Curricular Autonomy and Personal Development, the institution decided that teachers would be taught through activities designed and planned, with face-to-face sessions, if the students requested them.

Regarding the subjects of Curricular Autonomy and Personal and Social Development, lessons were carried out in three stages.

- First stage. Weekly activities were assigned (without a fixed schedule, but with an assigned day) that facilitated student learning according to what is expected in the subject, putting at their disposal the advisory service through web conference platforms.

- Second stage. The way of working on these types of subjects was modified so that the activity was delivered the same day assigned in the academic schedule.

- Third stage. To provide greater structure of student activities, a fixed class schedule was established on the assigned day, during which the student had to work and deliver their activity within the established schedule.

For Extracurricular Classes, the Student Leadership and Training Department, called "LIFE," contributed weekly to the area of sports. The LIFE department shared access links to allow others to see the activities corresponding to the disciplines of the students. In the cultural field, the sessions were personalized only at the beginning, while later the LIFE department sent out pre-recorded classes for the entire community.

Learnings and Experiences The main learnings and experiences are presented below:

- Keeping preteens and teens engaged with virtual activities has been complicated, and the academic administration and the emotional monitoring of these students carried out by the tutors was exhausting.

- Distance-format support and services for parents were complicated due to their lack of habit of use and lack of training on technological platforms, such as on the use of web conference platforms. Likewise, there was dissatisfaction from many families regarding the use of technological platforms as they believed these tools put minors' safety at risk.

- As the platform did not have a service that allowed the restriction of entry to only official participants, intruders in virtual classes occasionally prevented the class from taking place, annoying teachers and students.

- Little previous training for teachers, students, and parents complicated the development of many activities.

- The technological implications regarding the availability of suitable platforms for teaching classes must be fully analyzed. 
- Free-use platforms have limited functions; most of the time, full access is required, and most teachers did not have full access.

- Constant failures in Internet and electricity services in the city was a barrier for both teachers and students.

- Compliance with the requirements and provisions of the Secretary of Public Education of Guanajuato, as well as simultaneous compliance with the requirements and standards of Tecnologico de Monterrey, was a complicated activity for the staff.

- All institutional staff gave service and attention with an unlimited schedule, including on weekends, to meet the quality of service that has always distinguished the institution.

Challenges The challenges identified for this institution are summarized in Table 10.2.

\subsubsection{The Experience of the Bilingual Secondary School, Tec de Monterrey, Ciudad Juárez, Chihuahua, Mexico}

Context The Bilingual Secondary School, Tec de Monterrey-located in the city of Ciudad Juárez, Chihuahua, Mexico-is part of the Tecnologico de Monterrey System. The institution has about 452 students, divided among 20 groups in three grade levels and 65 teachers. This institution also applied the FDM to guarantee academic continuity during this global health emergency.

Implementation The pandemic originated days before the Easter holidays. Therefore, the institution used those days (1 week) to plan and prepare the virtual modality, attending to the proposed model (FDM) of the Tecnologico de Monterrey

Table 10.2 Challenges identified by the Bilingual Secondary School, Carlos Darwin, according to the defined three main stakeholders at this educational level

\begin{tabular}{l|l}
\hline Role & Identified challenges \\
\hline Teachers & $\begin{array}{l}\text { Constant teacher training } \\
\text { Access to emerging platforms (full access) } \\
\text { Challenge of migrating from the face-to-face classroom to digital formats } \\
\text { Avoid intruders in virtual classes } \\
\text { Ensure that students have acquired the expected knowledge } \\
\text { Availability of suitable platforms } \\
\text { Evaluation methods and tools to make online exams }\end{array}$ \\
\hline Students & $\begin{array}{l}\text { Constant failures in internet and electricity services } \\
\text { Emotional attention } \\
\text { Adequate use of tools }\end{array}$ \\
\hline Parents & $\begin{array}{l}\text { Lack of habit and training of technological platforms } \\
\text { Flexibility in guidance of parents } \\
\text { Parents being co-responsible for the learning process }\end{array}$ \\
\hline
\end{tabular}


University. The main strategy implemented to guarantee academic management, student monitoring, and academic continuity was the use of virtual classrooms with web conference platforms. This institution was also supported by "PrepaTec" campus Ciudad Juárez (high school of Tecnologico de Monterrey) since that institution has specific areas for teacher's training and information technologies support. Also, during the preparation week, a training program for the teachers was carried out to apply the stages that are recommended to transform a course into an FDM. This training program was mainly focused on the use of different technological tools and platforms.

Evaluation of Students As part of academic continuity, virtual classes were implemented. Nevertheless, classes were reduced by $75 \%$ to leave space so that the students were not connected all day (considering that they range in age from 12 to 15 years old). Teachers delivered online content and support through web conference platforms. Outside school hours, there were spaces available for advising in the subjects of mathematics and science. As was previously mentioned, there are three formal evaluation blocks during the academic period at the secondary education level. The contingency plan began with the beginning of the third block, so students completed projects to be evaluated in this last block. The delivery of activities has remained $90 \%$ delivered on time, another $6 \%$ delivered late, and about 20 students were irregular with their deliverables for a variety of reasons. Finally, some additional virtual platforms, such as Socrative, Quizlet, and Formative, were used to support these processes.

Learnings and Experiences The main learnings and experiences are presented below:

- There was good participation and attitude on the part of the teachers in the face of the challenge of migrating from face-to-face formats to digital formats.

- The variety of teaching tools used was increased.

- Most of the students, supervised at home or not, were aware of their classes and the delivery of their activities.

- Most student developed skills and competencies for handling and organizing many tasks.

- Better use of class time improved student discipline.

- It worked to check if the students were fine and to give them a little encouragement and hope when they needed it (improving their mood).

- There are teachers who have been unable to adapt and restructure their programs, giving too much "homework" work and giving long explanations in one session.

- Unfortunately, the student with the greatest need was not physically close, and his academic follow-up was difficult. Students with less maturity and little organizational and self-management skills were the most affected due to the large number of distractions they have at home as well as the lack of accompaniment.

Challenges The challenges identified for this institution are summarized in Table 10.3. 
Table 10.3 Challenges identified by the Bilingual Secondary School, Tec de Monterrey, according to the defined three main stakeholders at this education level

\begin{tabular}{l|l}
\hline Role & Identified challenges \\
\hline Teachers & $\begin{array}{l}\text { Find the ideal balance between remote connections and activities } \\
\text { Evaluation of platforms for the application of exams } \\
\text { Implementation of a specialized IT department } \\
\text { Better management of class time } \\
\text { Monitoring the mental health and well-being of teachers }\end{array}$ \\
\hline Students & $\begin{array}{l}\text { New engagement methods (due to the large number of distractions they have at home } \\
\text { and the lack of accompaniment) } \\
\text { Improve academic monitoring strategies } \\
\text { Programs for attend anxiety and frustration on students }\end{array}$ \\
\hline Parents & $\begin{array}{l}\text { Attend parent anxiety and frustration } \\
\text { Lack of a digital culture of parents } \\
\text { Student discipline support during classes }\end{array}$ \\
\hline
\end{tabular}

\subsection{Discussion}

Great challenges continue to arise not only in pedagogical practices but also in academic management processes. That is why today the design of new teachinglearning models and the design of good academic management practices-that incorporate emerging technologies in combination with appropriate activities, learning methods, and practices—need to be strengthened. Similarly, special attention is required for the key stakeholders in educational processes, including not only students and teachers but also parents and staff. Consequently, many areas of opportunity may emerge to serve the needs of key stakeholders, primarily at the elementary and secondary education levels. Finally, an opportunity is opening in research and development for the improvement of existing platforms, as well as the development of new technological tools and implementations considering areas such as remote labs and cyber-physical labs.

\subsection{Conclusions}

ICTs in Education 4.0 and specifically the use of virtualization and digitization tools in this sector have taken a relevant role, due to the global health emergency in 2020-2021 which has caused most students to re-join their classes through a distance learning format. Therefore, it was possible to design the Flexible-Digital Model (FDM) to ensure academic continuity in the different educational levels of this institution. Although the FDM was designed to be implemented in higher education, it was possible for it to be replicated in high school and secondary education levels. Due to the nature of each education level, the proposed model had to be adapted. The main reason is related to the different stages of life that students cross. In the case of the secondary level, some activities were redesigned to adapt to the 
requirement of students at this level and at these ages (12-15 years old). However, three relevant issues were observed to necessitate improvement during the implementation of the FDM at the secondary level: (i) the lack of connectivity and tools, (ii) the lack of a digital culture of teachers, students, and tutors/parents, and (iii) the lack of standard security programs related to minors in front of a webcam.

A general evaluation presented by the Tecnologico de Monterrey about the implementation of the FDM shows that most of the students $(63 \%)$ are very satisfied with the interaction with their teachers. Regarding the model and their learning experience, $44 \%$ of the students said they were very satisfied or satisfied, $35 \%$ gave a neutral opinion, and $21 \%$ were unsatisfied or very unsatisfied. The most frequent comments of dissatisfaction were about the workload and the duration of the classes.

Acknowledgments The authors would like to acknowledge the support of Dr. Pedro L. Grasa, Vice President of PrepaTec and Regional Development of Tecnologico de Monterrey, and the support of the Academic Vice-presidency of Educational Innovation of Tecnologico de Monterrey. Also, the authors would like to acknowledge the technical support of WritingLab, Institute for the Future of Education, Tecnologico de Monterrey, Mexico, in the production of this work.

\section{References}

Educational Model (Modelo Educativo) Tec21. (2019). Available from: http://modelotec21.itesm. $\mathrm{mx} /$ files/folletomodelotec21.pdf. Accessed 05 July 2019.

Forbes México. (2020). From: https://www.forbes.com.mx/que-detiene-a-la-educacion-en-linea/

Keser, H., \& Semerci, A. (2019). Technology trends, Education 4.0 and beyond. Contemporary Educational Research Journal, 9(3), 39-49.

C. Ma, W. Kuys, B. Kee, T. Howell, B. Steffensen, B. Cox, and U. Schulz, "Education 4.0: Innovation and entrepreneurship (catalyst case-study)" in the repository of vtc.edu.hk 2019.

Miranda, J., López, C. S., Navarro, S., Bustamante, M. R., Molina, J. M., \& Molina, A. (2019, June). Open innovation laboratories as enabling resources to reach the vision of education 4.0. In 2019 IEEE international conference on engineering, technology, and innovation (ICE/ ITMC) (pp. 1-7). IEEE.

Tecnológico de Monterrey, Educational Innovation Department. (2020). From: https://innovacioneducativa.tec.mx/transforma-flexible-digital/en/

Tecnológico de Monterrey, Educational Innovation Department. (2020). Report FDM. From https://innovacioneducativa.tec.mx/continuidad-academica-reporte/

Arturo Molina is Vice-Rector of Research and Technology Transfer and Researcher Professor at Tecnologico de Monterrey University in Mexico. He received the B.Eng. Degree in computational systems and the M.Eng. degree in computational sciences from the Tecnologico de Monterrey and his Ph.D. degree in Manufacturing Engineering at the Loughborough University of Technology and a University Doctor Degree in Mechanical Engineering at Technical University of Budapest, Hungary. He has co-authored more than 300 research articles and several inventions. His current research interests include concurrent engineering technologies and manufacturing, enterprise integration engineering, and technology management. He has applied research and development for the economic sectors of automotive, construction, and energy. He is a member of the Mexican National Researchers System, the Mexican Academy of Science, and the Mexican Academy of Engineering. 
Beatriz Villegas has worked for the Tecnologico de Monterrey for the last 30 years in different academic areas from higher education to secondary school level. For the last 18 years, she has been the School Principal of the Secundaria Bilingüe Carlos Darwin of the Tecnologico de Monterrey in Irapuato, Mexico. She received a bachelor's degree in Communication Sciences, and a master's degree in Education specialized in cognitive processes. She is certified as an Ontological Coach from the Newfield Consulting Group.

César Pavel Ochoa has a professional career at Tecnologico de Monterrey for 15 years, collaborating at the secondary level where he held positions of teacher, group tutor, coordinator of the IT area, admissions, and school control. He is currently the Director of the Bilingual Secondary School, Tec de Monterrey, Ciudad Juárez, Chihuahua, Mexico. He graduated as a Computer Systems Engineer from the Autonomous University of Chihuahua and has a master's degree in Telecommunications Administration from the Tecnologico de Monterrey. In his career, he has participated in the academic quality committees at the Tecnologico de Monterrey Campus Chihuahua and the implementation of the Olweus and Character Education programs at the Chihuahua Campus and Ciudad Juárez Campus.

Jhonattan Miranda is a Researcher in the Product Innovation Research Group at the Tecnologico de Monterrey University in Mexico. He received the B. Eng. degree in Mechatronics from the Tecnologico Nacional de México, Ciudad-Hidalgo Campus, Michoacan. His postgraduate studies were carried out at the Tecnologico de Monterrey, and he received an M.Sc. and a Ph.D. in Engineering Sciences with a concentration in Manufacturing Systems and Product Design, respectively. During his postgraduate studies, he was a visiting scholar at the Tecnologico de Costa Rica and the University of California, Berkeley. His current research interests include product design, open innovation, entrepreneurship, and educational innovation. He has co-authored different research articles in Manufacturing and Education and has a patent in micromachining. He is a member of the National Researchers System of Mexico.

Open Access This chapter is licensed under the terms of the Creative Commons Attribution 4.0 International License (http://creativecommons.org/licenses/by/4.0/), which permits use, sharing, adaptation, distribution and reproduction in any medium or format, as long as you give appropriate credit to the original author(s) and the source, provide a link to the Creative Commons license and indicate if changes were made.

The images or other third party material in this chapter are included in the chapter's Creative Commons license, unless indicated otherwise in a credit line to the material. If material is not included in the chapter's Creative Commons license and your intended use is not permitted by statutory regulation or exceeds the permitted use, you will need to obtain permission directly from the copyright holder.

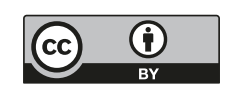

